\title{
Chabet at Finale Art Gallery
}

\author{
Nonon G. Padilla
}

Just came from the exhibit of Bobby Chabet at Finale Art File. He filled the floor with corrugated steel sheets and lit them with halogen lamps to create a sea of "memory" that recalls his youth in war-torn Manila.

Impressive and infuriating: it's the kind of show that tells the art viewer that he's looking at ephemeral art, non-commercial and uncompromisingly unmarketable!

It was held at the new space of Vita Sarenas at Pasong Tamo, a huge warehouse esplanade. I wonder if Vita realizes that Bobby's work is a joke on her commercialism.

She nonetheless has to feature him since practically all her new artists were or still are his students.

Bobby's art-making has always been tough and uncompromising. In the mezzanine he installs orange neon lights that spell: ONETHINGAFTERANOTHER-a reference to Donald Judd's aesthetic aspiration of spareness and transience.

In the lower floor the lights reflect on the steel sheets to create a shimmering array of dancing waves, as you, the viewer, move around the space. I am tempted to go back there with my toy helicopter, with a remote control, and let it fly across the space while playing full blast on a cd player Wagner's The Valkyrie, to complete the experience.

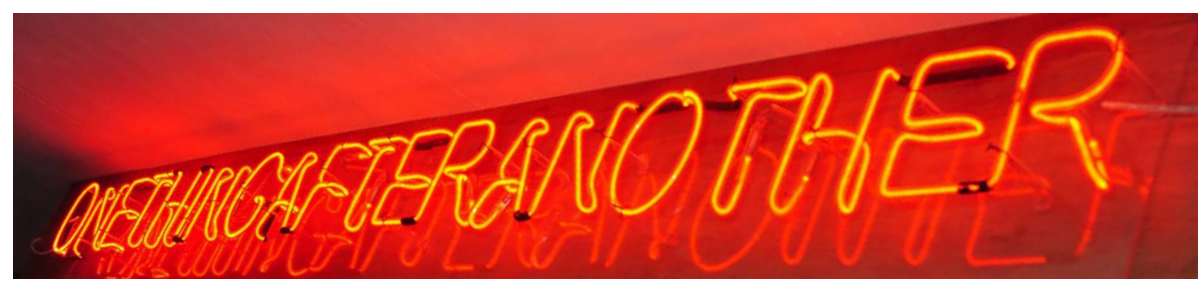


Nonon G. Padilla, "Chabet at Finale Art Gallery"

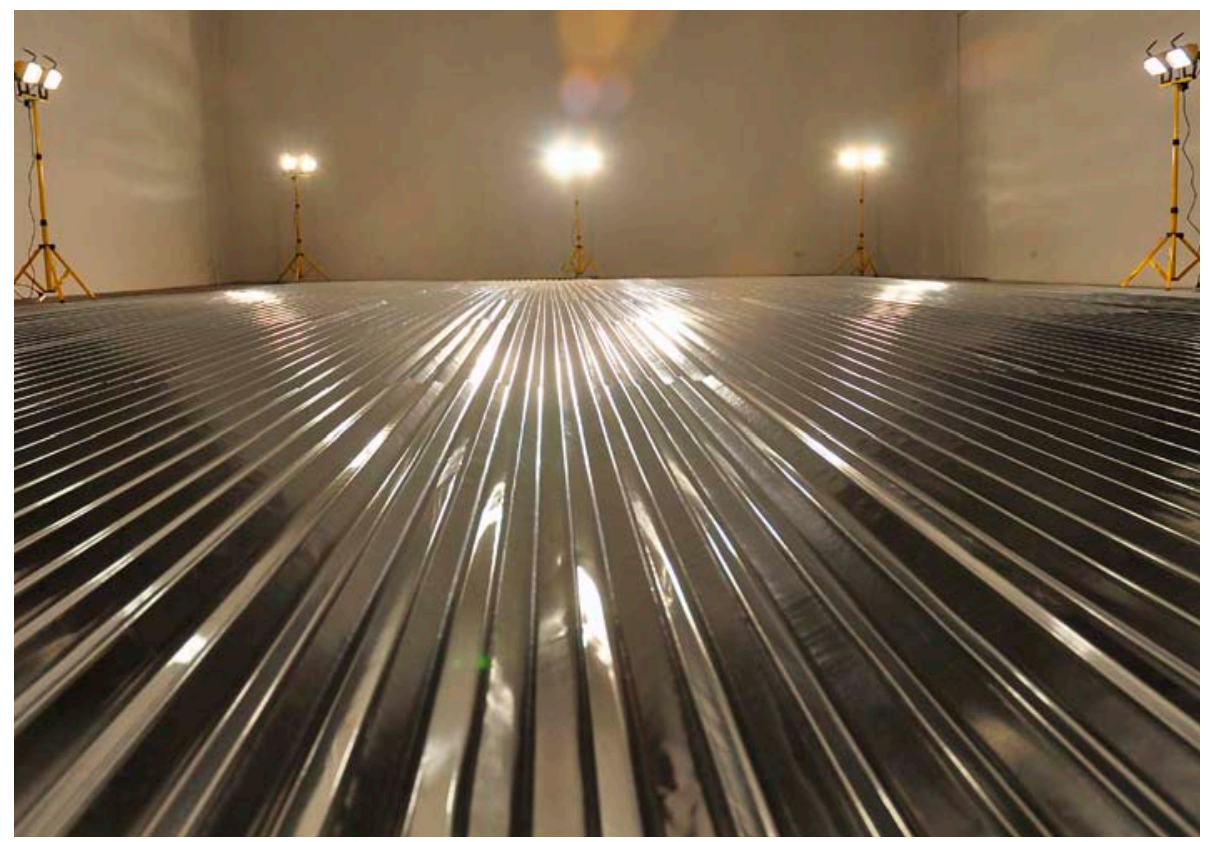

At the mezzanine you get a different light experiment. Instead of reflected light, you get the glow of the neon light bathing the white walls. When you enter the inner room, which he calls the "womb," you get another room with yet another neon installation that also glows, bathing the white walls with a soft, pale orange. It's supposed to complement, I guess, the statement at the lower floor where steel sheets reflect light.

Bobby is painting, not with pigment but with steel sheets enhanced by halogen lamps. And he's painting horizontally instead of vertically as with traditional painting. The experience is very Japanese in one sense, and ironic in another. It's a refreshingly poetic experience. And I urge you to go see it for yourself.

He turned Vita's Gallery into a space like the DIA Foundation in Soho, New York that shows unmarketable art installations. I love him for twitting silly Manila's Art Market. 